\title{
Menstrually Related Changes and Disorders: Conceptualization and Diagnostic Considerations
}

\author{
Uriel Halbreich, M.D.
}

Four decades ago, a distinguished panel of clinicians and academicians gathered "to establish the syndrome of premenstrual tension (PMT) as a clinical entity and to point the way to a better understanding of its etiology and treatment" (Morton 1953). They were concerned that "with an incidence of about $50 \%$ of all menstruating women, premenstrual tension must be regarded as the most common "nervous" disorder of women" and "the condition cannot be dismissed as being neurotic or primarily psychogenic." The panelists concluded:

It is obvious that disagreement exists concerning the specific pathogenesis of PMT. It is also apparent that one or more of the symptoms may predominate in any one patient and for that reason, the etiologic pattern is not necessarily identical in every instance. . . . It would appear therefore that the problem of the etiology of PMT requires further investigation.

It is disheartening that 40 years after the panel and 60 years after Frank's (1931) pioneering reports on PMT, literally dozens of papers include statements like "the etiology of Premenstrual syndrome (PMS) is still obscure" and "agreed upon definition and criteria are needed."

The report of the American College of Neuropsy-

From the Departments of Psychiatry and Obstetrics/Gynecology, State University of New York, Buffalo

Address correspondence to: Uriel Halbreich, M.D., Professor of Psychiatry and Research Professor of OB/GYN, State University of New York at Buffalo, 462 Grider Street, Clinical Center, Buffalo, New York 14215.

Received December 4, 1992; revised January 22, 1993; accepted January 27, 1993. chopharmacology ACNP study group (Halbreich et al. 1993) is an attempt to delineate the points of consensus and disagreement in the field, which we believe is the first step toward the development of broadly accepted operational criteria and interdisciplinary cooperation. The main issues raised by the four commentators (who did not participate in the study group) are as follows. 1) Is the delineation of a list of points really productive? 2) Is an alternative to the DSM-III-R and DSM-IV "premenstrual dysphoric disorder" entity necessary? 3) Is suppression of ovulation effective as a treatment for PMS; is surgical menopause justified for that purpose? 4) What is the role of serotonin in the pathophysiology of PMS; what can we learn from the efficacy of serotonergic agonists as treatment for dysphoric PMS? 5) What are the roles of the environment and psychosocial factors in the formation or expression of PMS? I strongly believe to achieve a substantial progress in this field that an attempt at integration should be made. Diagnostic as well as treatment issues cannot be separated from pathophysiology. The pathophysiology is multidimensional and symptoms cannot be attributed to a single factor. Indeed, the environmental and psychosocial aspects interact with the biological ones. Therefore, the points raised by the commentators will be addressed in an integrative solution-oriented way, instead of a point-to-point response that at least partially would be repetitious of the study group report.

During the last decade, a task force of the American Psychiatric Association (APA) has undertaken a commendable effort to examine PMS within the context of the APA's Diagnostic and Statistical Manual, 3rd edition revised (DSM-III-R, 1987), to accommodate "an urgent need for diagnostic criteria to differentiate cases 
of PMS in which disturbance of mood predominates, from cases of PMS with only physical symptoms" (Spitzer et al. 1989). An attempt to achieve a consensus on operational criteria for this prevalent state (Davis 1985; Williams et al. 1983) resulted in the definition of late luteal phase dysphoric disorder (LLPDD), which has been included in the appendix as a "Proposed diagnostic category needing further studies." The criteria for LLPDD represent a descriptive approach to allow for "research evidence to accumulate, that either validates or negates the utility of this diagnostic construct" (Spitzer et al. 1989). It appears that the task force for DSM-IV adheres to the descriptive phenomenologic approach and the emphasis on the premenstrual period. It is suggested here that cumulative research might be interpreted as questioning the utility of LLPDD or "premenstrual dysphoric disorder" as they are currently constructed, and the need to completely differentiate cases of dysphoric PMS from physical PMS can also be open for discussion.

One important prerequisite to the elucidation of the etiology of PMS, as well as to the development of appropriate treatment modalities, is the recognition that menstrually related changes (MRCs), including PMS, represent a multidimensional interdisciplinary issue which is best dealt with by an interdisciplinary collaborative effort (e.g., ISPOG 1989, 1992; Halbreich et al. 1988). The first step in a productive collaboration is the delineation of points of consensus as well as disagreements (as has been done by the 1991 study group), and then to agree upon a working conceptualization and a definition of the entity (or entities) in focus. Here a departure from the current phenomenologydescriptive thinking will not only provide a common denominator but might also be conceptually more productive. The biological and diagnostic data supporting the following suggestions were reviewed by us in great detail (Halbreich et al. 1988). To avoid redundancy and another lengthy review, only their relevant essence will be summarized here.

In the formulation of a framework for MRCs, some observations might be widely accepted and might serve as common denominators and a foundation for a factually based conceptualization. 1) The phenomenology of menstrually related changes is diversified and reflects involvement of many body systems including changes in mood and behavior, water retention, mastalgia, pain in various organs, migraine, changes in circulatory and autonomous systems, skin disorders, allergies and asthma, epilepsy, and numerous other changes (over 200 symptoms have been reported) (Halbreich et al. 1982; Dalton 1985). 2) Many times clusters of symptoms (syndromes) can be identified, but sometimes a woman has only a single dominant symptom (e.g., asthma, temporal lobe epilepsy, a skin disorder) that appears cyclically and is usually entrained to the menstrual cy- cle. 3) Some women experience positive changes during the late luteal phase (e.g., increased energy and productivity, increased affection). 4) None of the symptoms per se is exclusively related to the menstrual cycle; similar symptoms might appear during other periods of life and most of them (excluding mastalgia and other gender specific symptoms) are also experienced by men. 5) A statistical association between dysphoric luteal symptoms and lifetime history of Major Depressive Disorder (MDD) has been reported, and women diagnosed as having dysphoric PMS might be more vulnerable to develop MDD in the future. 6) Cyclical symptoms tend to appear mostly during the lateluteal phase, but many women report symptoms during longer periods and even the entire luteal phase. In some women the symptoms continue well into the menstrual period (they are distinguished from dysmenorrhea) (Bancroft 1989) and are perimenstrual. Some women report periovulatory symptoms. Although symptoms appear during or shortly after periods of hormonal fluctuations, they usually do not appear during the more stabile midfollicular phase. 7) Chronic disorders (including MDD, epilepsy) may exacerbate or worsen during the luteal phase. Sometimes their exacerbation can be prevented by adjustment of dosing of maintenance drugs according to phase of the menstrual cycle (Halbreich and Carson 1989). 8) Treatment-response reports demonstrated that suppression of ovulation with gonadotropinreleasing hormone agonists or danazol have been beneficial for elimination of menstrually related phenomena as diverse as severe dysphoria, porphyria, lupus erythematosus, epilepsy, and skin disorders (Muse et al. 1984; Watts et al. 1985; Magos et al. 1986; Bancroft et al. 1987; Anderson et al. 1984). Similar results were also reported following surgical menopause by ovariectomy, but as Dr. Steege commented such a radical approach is hardly justified when similar therapeutic benefits can be achieved pharmacologically. 9) Many symptoms similar to MRC might be aggravated by, or are side effects of, contraceptive pills (Cullberg 1972; Kane et al. 1967). 10) Women with MRC are probably also more vulnerable to symptoms during other periods of instability or change, such as, postpartum, following abrupt hormonal withdrawal, and during menopause. There is probably an association between having MRC and Seasonal Affective Disorder. 11) The cyclicity of symptoms is usually eliminated during spontaneous anovulatory cycles (Backstrom et al. 1989), during pregnancy, and following menopause. 12) Cyclic PMS-like symptoms can be simulated in postmenopausal women by treatment with sequential contraceptive pills (Hammerback et al. 1985). 13) Symptoms were reported to appear with a time lag of 5 to 6 days after changes in levels of gonadal hormones (Halbreich et al. 1986; T. Backstrom, personal communication). 14) Absolute levels of gonadal hormones do not 
necessarily distinguish between women with and without PMS (Rubinow et al. 1988). 15) Curtailment of the late luteal phase does not eliminate symptoms (Schmidt et al. 1991). 16) Appropriate symptomatic treatment is sometimes but not always beneficial. Its efficacy is limited to subgroups of women with specific Premenstrual syndromes (Magos 1989). For example, as was emphasized by Dr. Brown, some serotonergic agonists have been reported to be very effective as treatment of dysphoric PMS. 17) As was emphasized by Dr. Severino, environmental influences, responses to stressors, coping styles, and attribution play an important role in the expression of MRC.

The above data can be conceptualized as follows. 1) Most, if not all, menstrually related changes might be related to the same generalized underlying mechanism that is probably at least partially related to events preceding, associated with, or following ovulation. 2) Cyclic changes in the hypothalamo-pituitary-gonadal (HPG) system, its regulation and relationship with other systems, are putatively playing an important role in the underlying mechanisms of MRC. 3) These changes might trigger changes in other systems. Even if the activity and changes of the HPG system are "normal," in some individuals, affected systems might be more vulnerable to dysregulation. 4) The changes in the HPG system are probably part of a destabilizing process that might cause impaired homeostasis and a decrease in threshold for surfacing or expression of symptoms. 5) The nature and constellation of symptoms depend on individual proneness and vulnerability. (The diversity of symptoms might be explained by the individual vulnerability traits as well as the multiple systems that are involved in the impaired homeostasis.) 6) Treatment might be aimed at the generalized underlying mechanism (e.g., fluctuation in the regulation and interactions of the HPG system) or at a symptomatic relief of the individual's vulnerability and determined subtype of MRC (e.g., serotonergic reuptake inhibitors).

The conceptualization of a putative underlying physiology of MRC is summarized in the upper part of the integrative Table 1 . The possible relevant diagnostic phenomena and entities are summarized in the table under each physiologic stage, starting from generalized MRC and leading to the system-oriented symptomatic subtypes. According to this approach, the variety of dysphoric or physical premenstrual (or perimenstrual) syndromes and disorders might be considered as subtypes of MRC. The treatment implications of each stage are summarized in the lower part of the table. (In cases of system-oriented symptomatic subtypes, a targeted symptomatic treatment might be effective.)

Based on this conceptualization, it is suggested that the definition of premenstrual and other menstrually related changes should be based mostly on a temporal occurrence and not on phenomena: on the timing of the appearance and disappearance of changes and not on their description. The main diagnostic issue is "when" rather than "what." In the case of premenstrual changes (PMCs), any symptom may occur premenstrually, and as long as it is occurring cyclically and is essentially limited to the luteal phase, it is a premenstrual change. In most women PMCs consist of multiple symptoms; in others only a single change might be dominant. Because at present no difference in any underlying mechanism has been demonstrated between changes of different lengths or menstrual cycle timing (e.g., symptomatic period of 1 to 2 days versus entire luteal phase), although they all share the aforementioned common denominators, the overall term MRCs might be more accurate.

Table 1. Menstrually Related Changes: Summary of Mechanism, Diagnoses, and Treatment

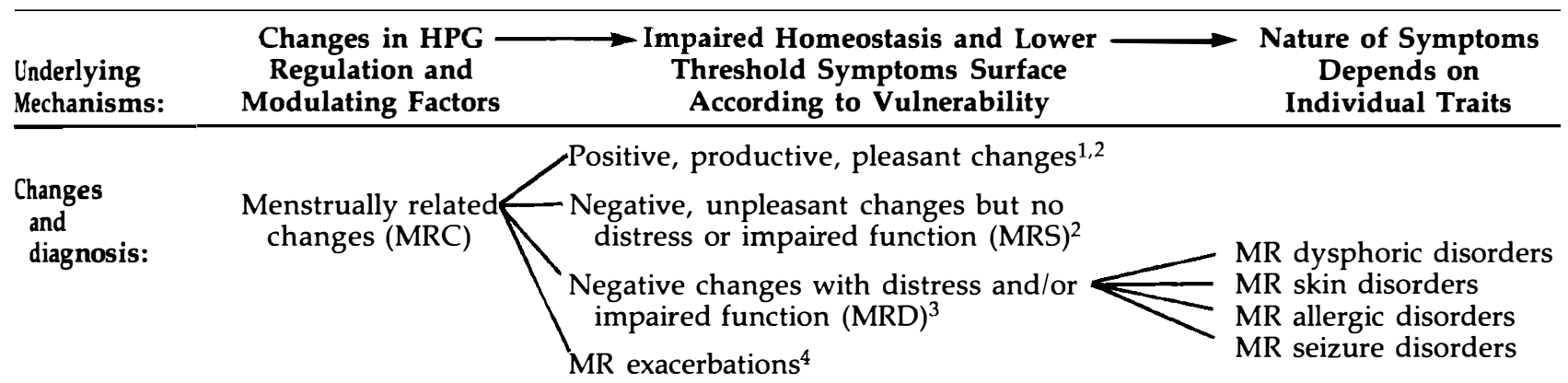

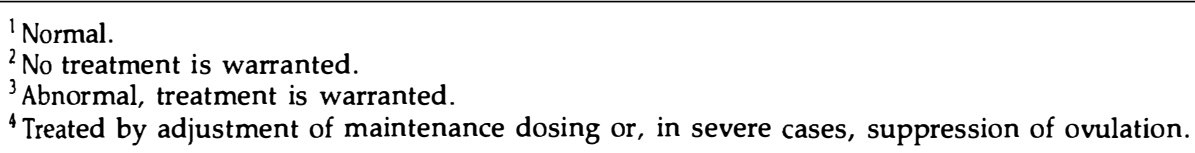


This suggested conceptualization implies another departure from current concepts. If the main mechanism of MRC is a menstrually related dysregulation or a decrease in threshold, and specific symptoms appear or worsen according to individual vulnerability, then menstrually related exacerbations or a menstrual cycle-entrained worsening of a chronic disease might be considered under the same umbrella. (Indeed the main diagnosis should be according to the main underlying mechanism with a qualifier of MRD.) It might be a subject for future research to ascertain whether hormonal interventions are of benefit in reduction of these exacerbations. The significance of underlying mechanisms of the various subtypes of MRC in relation to the stimulus inducer of symptoms in a particular timing is still debatable and is also a subject for future research.

Apparently the suggestion that the same underlying mechanism might trigger diversified, sometimes nonoverlapping phenomena in different individuals, and therefore people with completely different signs and complaints (e.g. skin disorders and epilepsy) might carry the same diagnosis and be identically treated, is currently not widely accepted. However, this is also the case with disseminated disorders (e.g., Rheumatic disease, Systemic Lupus Erythematosus, Multiple Sclerosis). An integrative and cross disciplinary reading of the available literature can lead to the conclusion that this might also be the case with MRC.

Hopefully, the ideas presented here will stimulate conceptualization and research of multidimensional processes that are clinically manifested in diversified sets of signs and symptoms. But above all, they provide a common denominator for interdisciplinary cooperation. A multidisciplinary task force is needed to develop a generalized set of operational criteria that reflect input from psychiatry, gynecology, endocrinology, general medical practice, psychology, and epidemiology (among others). Only then should symptom-specific subtypes be developed by the relevant specialties. To enhance and promote the acceptance and use of diagnostic categories across medical specialties, such a task force should be under the aegis of a unifying organization such as the American Medical Association or the World Health Organization. Hopefully, such a timely interdisciplinary initiative will be pursued in the near future.

\section{ACKNOWLEDGMENTS}

This paper is a general response to the preceding commentators. The concepts and criteria were presented and discussed, among others, at the Ninth International Congress of Psychosomatic OB/GYN (ISPOG), Amsterdam, May 1989 and the Annual Meeting of the American College of Neuropsychopharmacology (ACNP), San Juan, December 1991.

Preparation and work leading to this publication have been partially supported by National Institute of Mental Health Grants RO1-MH45246 and RO1-MH46901.

\section{REFERENCES}

American Psychiatric Association (1987): Diagnostic and Statistical Manual of Mental Disorders, Third Edition Revised. Washington, DC, APA Press, pp 367-369

Anderson KE, Spitz IM, Sassa S (1984): Prevention of cyclical attacks of acute intermittent porphyria with a long acting agonist of LH-RH. N Engl J Med 311:643-645

Backstrom T, Hammerback S, Johansson U-B (1989): Etiolog. ical aspects of menstrual cycle linked mood changes. In van Hall EV, Everland W eds, The Free Woman. Park Ridge and Carnforth, Parthenon Publ, pp 625-632

Bancroft J (1989): Perimenstrual mood change and depressive illness. Abstract presented at the regional congress of Societies of Biological Psychiatry, Jerusalem, Israel, April 2-7, 1989 (Published by the WFSBP in the program, p 75)

Bancroft J, Boyle H, Warner P, Frazer HM (1987): The use of an LHRH agonist, buserlin, in the long term management of premenstrual syndromes. Clin Endocrinol 27: 171-182

Cullberg J (1972): Mood changes and menstrual symptoms with different gastagen/estrogen combinations. Acta Psychiatr Scand 236 (Suppl 1):1-84

Dalton K (1985): The Premenstrual Syndrome and Progresterone Therapy. London, William Heneman

Davis M (1985): Premenstrual Syndromes. In Report of the Public Health Task Force on Women's Health, Vol. 2. Washington, DC, Government Printing Office, pp 80-85

Frank RT (1931): The hormonal causes of premenstrual tension. Arch Neurol Psychiatry 26:1053-1057

Halbreich U, Carson S (1989): Drug studies in women of child bearingage: Ethical and methodological issues. J Clin Psychopharmacol 9:328-333

Halbreich U, Endicott J, Schacht S, Nee J (1982): The diversity of premenstrual changes as reflected in the Premenstrual Assessment Form. Acta Psychiatr Scand 65:46-65

Halbreich U, Endicott J, Goldstein S, Nee J (1986): Premen. strual changes and changes in gonadal hormones. Acta Psychiatr Scand 74:576-585

Halbreich U, Alt IH, Paul L (1988): Premenstrual changes: Impaired hormonal homeostasis. Endocrinol MetabClin North Am 17:173-194

Halbreich U, Bancroft J, Dennerstein L, Endicott J, Faccinetti F, Genazzani A, Morse C, Parry B, Rubinow D, Reid R, Schiff I, Smith S, Backstrom T (1993): Menstrually related disorders: Points of consensus, debate, and disagreement. Neuropsychopharmacology 9:1-12

Hammerback S, Backstrom T, Holst J, von Schoulter B Lyrenas S (1985): Cyclical mood changes as in the premenstrual tension syndrome during sequential estrogen-progestagen postmenopausal replacement therapy. Acta Obstet Gynecol Scand 64:515-518

Kane FJ Jr, Daly RJ, Ewing JA (1967): Mood and behavioral changes with progestational agents. Br J Psychiatr! 113:265-268 
Magos AL (1989): Treatment of PMS. In van Hall EV, Everland W eds, The Free Woman. Park Ridge and Carnforth, Parthenon Publ, pp 659-666

Magos AL, Brincat M, Studd JW (1986): Treatment of the premenstrual syndrome by subcutaneous estradiol implants and cyclical oral norethisterone: Placebo controlled study. Br Med J 292:1629-1633

Morton JH (1953): Symposium on premenstrual tension. Internatl Rec Med 166:463-510

Muse KN, Cetel NS, Futterman LA, Yen SSC (1984): The premenstrual syndrome, effects of medical ovariectomy. N Engl J Med 311:1345-1349

Ninth International Congress of ISPOG (1989): Abstracts. J Psychosom Ob/Gyn 10 Suppl 1:3-314

Rubinow DR, Hoban MC, Grover GN, Gallaway DS, RoyByrn P, Andersen R, Merriam GR (1988): Changes in plasma hormones across the menstrual cycle in patients with menstrually related mood disorder and control subjects. Am J Obstet Gynecol 158:5-11

Schmidt PJ, Nieman LK, Grover GN, Muller KL, Merriam GR, Rubinow DR (1991): Lack of effect of induced menses on symptoms in women with premenstrual syndrome. N Engl J Med 324:174-179

Spitzer RL, Severino SK, Williams JBW, Parry BL (1989): Late luteal phase dysphoric disorder and DMS III-R. Am J Psychiatry 146:892-897

Tenth International Congress of ISPOG (1992): Abstracts. J Psychosom Ob/Gyn 13 (Suppl 1):1-288

Watts JF, Edwards RL, Butt WR (1985): Treatment of premenstrual syndrome using danazol: Preliminary report of a placebo-controlled, double-blind dose ranging study. J Intern Med Res 13:127-128

Williams JCG, Martin AJ, Hulkenberg-Tromp TE (1983): PMS in four European countries: A double blind placebo controlled study of dyhydro-progesterone. Br J Sex Med 10:8 